\title{
¿Demonstration of a Remotely Piloted Atmospheric Measurement and Charge Release Platform for Geoengineering
}

\author{
R. Giles Harrison, ${ }^{a}$ Keri A. Nicoll,,${ }^{\mathrm{a}, \mathrm{b}}$ Douglas J. Tilley, ${ }^{\mathrm{b}}$ Graeme J. Marlton, ${ }^{\mathrm{a}}$ Stefan Chindea, ${ }^{\mathrm{b}}$ \\ Gavin P. Dingley, ${ }^{\mathrm{b}}$ Pejman Iravani, ${ }^{\mathrm{c}}$ David J. Cleaver, ${ }^{\mathrm{c}}$ Jonathan L. Du Bois, ${ }^{\mathrm{c}}$ AND David BRUs ${ }^{\mathrm{d}}$ \\ ${ }^{a}$ Department of Meteorology, University of Reading, Reading, United Kingdom \\ ${ }^{\mathrm{b}}$ Department of Electronic and Electrical Engineering, University of Bath, Bath, United Kingdom \\ ${ }^{\mathrm{c}}$ Department of Mechanical Engineering, University of Bath, Bath, United Kingdom \\ ${ }^{\mathrm{d}}$ Finnish Meteorological Institute, Helsinki, Finland
}

(Manuscript received 26 June 2020, in final form 14 October 2020)

\begin{abstract}
Electric charge is always present in the lower atmosphere. If droplets or aerosols become charged, their behavior changes, influencing collision, evaporation, and deposition. Artificial charge release is an unexplored potential geoengineering technique for modifying fogs, clouds, and rainfall. Central to evaluating these processes experimentally in the atmosphere is establishing an effective method for charge delivery. A small charge-delivering remotely piloted aircraft has been specially developed for this, which is electrically propelled. It carries controllable bipolar charge emitters (nominal emission current $\pm 5 \mu \mathrm{A}$ ) beneath each wing, with optical cloud and meteorological sensors integrated into the airframe. Meteorological and droplet measurements are demonstrated to $2 \mathrm{~km}$ altitude by comparison with a radiosonde, including within cloud, and successful charge emission aloft verified by using programmed flight paths above an upward-facing surface electric field mill. This technological approach is readily scalable to provide nonpolluting fleets of charge-releasing aircraft, identifying and targeting droplet regions with their own sensors. Beyond geoengineering, agricultural, and biological aerosol applications, safe ionic propulsion of future electric aircraft also requires detailed investigation of charge effects on natural atmospheric droplet systems.
\end{abstract}

KEYWORDS: Atmospheric electricity; Cloud droplets; In situ atmospheric observations; Weather modification

\section{Introduction}

Electricity in the atmosphere has long been supposed to influence clouds of water droplets. For example, Luke Howard (1772-1864), whose cloud nomenclature system is still widely used, stated that in nimbus (rain) clouds, water drops "are by a change in their electrical state made to coalesce, and descend in drops of Rain" (Howard 1843). This assertion probably arose from the then fashionable interest in electrostatics rather than observations, but Lord Rayleigh subsequently reported direct experiments in which "instead of rebounding after collision, as the unelectrified drops of water generally or always do, the electrified drops coalesce" (Strutt 1879). More recent experimental and theoretical work (e.g., summarized in Pruppacher and Klett 1998) has confirmed that charge does indeed influence droplet collisions and coalescence, and empirical findings indicate that regional ionization release is associated with precipitation changes (Harrison et al. 2020). Highly charged droplets are also known to disintegrate under intense electric forces (Rayleigh 1882; Duft et al. 2003). Here we demonstrate a new enabling technology to modify droplet electrostatics as a potential geoengineering technique, through releasing charge from a remotely controlled platform capable of entering clouds or aerosol regions.

\footnotetext{
Denotes content that is immediately available upon publication as open access.

Corresponding author: R. Giles Harrison, r.g.harrison@reading. ac.uk
}

We describe a remotely piloted aircraft [also known as an unmanned aircraft system (UAS)] from which ions of either polarity can be released in a regularized manner, also providing an onboard measuring capability with which the local droplet, thermodynamic and electrical conditions can be monitored.

A great advantage of charge release as a possible geoengineering approach using airborne platforms is that large volumes of modifying substance are not required to be carried aloft. It is consequently well suited to the capabilities of small remotely piloted aircraft (RPA), equipped with charge emitters and monitoring instrumentation, as summarized in Fig. 1. The technology developed is described here. Section 2 assesses the requirements for an ion release system from which generated ions ultimately become attached to water droplets, charging them. Section 3 describes the charge emission and meteorological sensing technology developed and section 4 the integration of this technology with an aircraft. Addressing the practical difficulties of flying beyond visual line of sight into clouds is a further essential aspect, to obtain good operating duration (tens of minutes) at significant altitude (to several kilometers). Section 5 describes trials of the system in specially arranged airspace and section 6 evaluates the charge emission.

For such a widespread and fundamental influence as electrostatics on droplet behavior there are many other associated applications, including in biology, for which droplet charging is recognized to enhance insect and foliage deposition (Gaunt et al. 2003; Inculet et al. 1981). Investigating the effect of charge on the efficiency of airborne aerosol sampling provides a further application. Beyond aerosol physics, biological systems and geoengineering, additional motivation is provided by the need to 


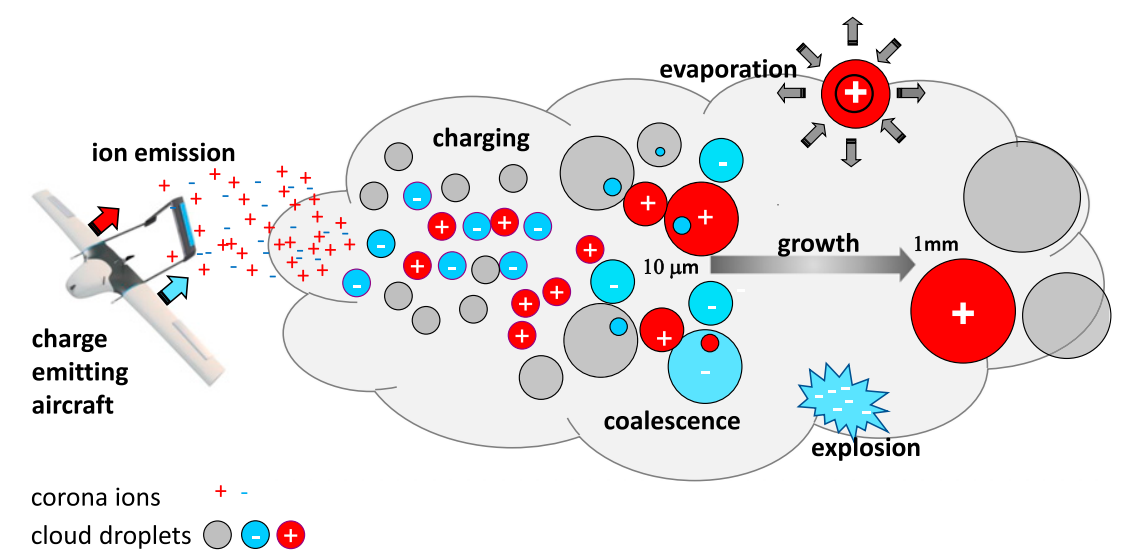

FIG. 1. Conceptual picture of charge emission, droplet charging, and droplet growth in a cloud (drawn to show droplet growth left to right). Corona ions released by an aircraft become entrained into the cloud, charging the water droplets present by attachment of the ions. Charging of the droplets modifies the droplet-droplet coalescence, influencing the growth rate to large drops that ultimately fall out of the cloud as rain. (Droplets lost by evaporation, or in the case of highly charged drops, charge-induced explosions which occur through electrical instability, are indicated at the cloud boundaries.)

explore atmospheric consequences of future electric propulsion of aircraft by ion emission and the concept of using ion emission to neutralize the charge on aircraft to prevent the triggering of lightning (Xu et al. 2018; Ieta and Chirita 2019). The net electrostatic effects within natural aerosol systems, and their influence on detailed microphysical droplet processes leading to rain, can be investigated with the new experimental capabilities described.

\section{Charge release considerations}

Charging of water droplets can be achieved by release of air ions into the droplet region (e.g., Gunn 1954). The charge modifies the behavior of the droplets, especially that concerned with droplet-droplet collisions. This is now discussed further, together with estimates of the charge required and generated.

\section{a. Properties of charged droplets}

When a charged water droplet approaches another water droplet, charged or uncharged, it induces a charge in the second droplet, which induces a further charge in the original droplet, repeating indefinitely. Charged, colliding water droplets therefore experience an infinite system of electrostatic image charges between them, with associated electric forces (Thomson 1853; Russell 1922; Davis 1964). Formally, the net dropletdroplet force is always attractive at small separations regardless of the droplets' relative polarities, unless the exact ratios of their charges would make them an equipotential on contact (Lekner 2012; Banerjee and Levy 2015). With natural variability, this unique equipotential condition is unlikely to occur, hence two colliding charged cloud droplets can be generally considered as being more likely to coalesce than two neutral droplets. Therefore, if cloud droplets can be charged artificially, the electrical influence on coalescence may, in turn, hasten the generation of rain (Harrison et al. 2015). Another application for artificial charge dispersal might arise from the practical need to remove droplet or aerosol charge, such as in the case of release of radioactive aerosol, which can become sufficiently highly charged to be preferentially washed to the surface by water droplets (Tripathi and Harrison 2001).

Release of corona ions into fogs and clouds has been contemplated previously and considered for possible hydrological and electrical benefits. After observing a fog near a high voltage tower, the inventor and electrical engineer, Nikola Tesla (1856-1943), said "I am positive ... that we can draw unlimited amounts of water for irrigation" (Cheney 2001). The most wellknown artificial charge release work is probably that of Vonnegut and Moore, in which corona ions were released from near-surface high voltage horizontal wires $14 \mathrm{~km}$ long (Vonnegut et al. 1962a,b). With this apparatus, it was demonstrated that the charge released modified the initial electrification of small cumulus clouds. Later work (Phelps and Vonnegut 1970) estimated the charging needed to influence the droplet growth.

\section{b. Requirements for charge release}

Introducing charge into an aerosol or cloud can be achieved through surface or airborne release of air ions. Surface emission systems require extensive installations, and depend on natural updrafts and entrainment processes to allow the generated ions to reach and enter aerosols or clouds. As substantial quantities of ions can be generated relatively easily, the inefficiency of the vertical transport process may not matter in allowing some additional ions to ultimately reach and enter clouds, through following natural updraft routes. The disadvantage is that, even with large quantities of charge generation at the surface, assessment of any consequent effects will be complicated by the wide spatial dispersion of ions likely to be encountered. Using aircraft to provide targeted charge release controlled from the surface provides a promising alternative, allowing cloud regions to be located where small droplets, 
which are those most likely to be influenced electrically, are more abundant. In addition, because charge can be generated easily electrically, there are no substantial payload requirements and hence small aircraft are particularly suitable.

Although more detailed work at local scales is needed to fully evaluate the charge required to influence natural aerosols and clouds, some bounding estimates can be made. The regional-scale cloud and precipitation changes reported by Harrison et al. (2020) were associated with an approximate doubling of the natural ion concentration. Over land surfaces, the typical volumetric ion production rate $q_{0}$, is about $10^{7}$ ion pairs $\mathrm{m}^{-3} \mathrm{~s}^{-1}$ (Chalmers 1967). This reduces with height, before increasing from cosmic ray ionization above about $3 \mathrm{~km}$. If clear air is considered (i.e., neglecting ion removal to aerosol or droplets), the steady-state mean ion number concentration $n_{0}$ is given by

$$
n_{0}=\sqrt{\frac{q_{0}}{\alpha}},
$$

where $\alpha$ is the ion-ion recombination rate $\left(1.6 \times 10^{-12} \mathrm{~m}^{3} \mathrm{~s}^{-1}\right)$. For $q_{0}=10^{7} \mathrm{~m}^{-3} \mathrm{~s}^{-1}$, this gives $n_{0}=2500 \times 10^{6} \mathrm{~m}^{-3}$ (Harrison and Carslaw 2003).

For an air ion generator operating by corona emission, the associated unipolar ion production rate, neglecting recombination, is directly proportional to the current flowing to the emitter tip. If the corona current is $I_{c}$, the corona ion production rate $R_{c}$ will be

$$
R_{c}=\frac{I_{c}}{e},
$$

where $e$ is the elementary charge $\left(1.6 \times 10^{-19} \mathrm{C}\right)$. If the aircraft is in level flight at a speed $v$, and air ions are emitted in a cylindrical beam of cross section area $S$, the instantaneous number of unipolar ions $\left(n_{c}\right)$ generated per unit volume due to corona is

$$
n_{c}=\frac{R_{c}}{S v}=\frac{I_{c}}{S v e}
$$

The current required to generate an instantaneous corona ion concentration which is a multiple $f$ of the steady-state background ion concentration $n_{0}$ (i.e., $f=n_{c} / n_{0}$ ), is therefore

$$
I_{c}=f S v e \sqrt{\frac{q_{0}}{\alpha}} .
$$

For a small aircraft (1 m wingspan) flying at $v=30 \mathrm{~m} \mathrm{~s}^{-1}$, emitting an ion plume into an area defined by the wingspan (i.e., $S=1 \mathrm{~m}^{2}$ ), $I_{c}$ is found from Eq. (4) for $f=1$ as $\sim 10^{-8}$ A. If, as observing smoke plume releases from small aircraft suggests, the emitted ion plume spreads vertically by up an order of magnitude more, $S \sim 100 \mathrm{~m}^{2}$ and the associated $I_{c}$ required is $\sim 10^{-6} \mathrm{~A}$. Emission currents of at least $10^{-6} \mathrm{~A}$ (i.e., $1 \mu \mathrm{A}$ ) are realizable, hence $f \gg 1$ from a practical emission system is readily obtained. The total cloud volume into which ions are released is determined by the flight path and duration.

An alternative perspective was provided by Phelps and Vonnegut (1970), who estimated that, to increase the coalescence efficiency of droplets to near $100 \%$, an oppositely charged droplet carrying an order of magnitude more charge than the surrounding droplets would be needed. Takahashi (1973) showed that the average charge on a droplet in a warm cloud was approximately $1 \times 10^{-17} \mathrm{C}(\sim 60|e|)$ Thus, for enhanced coalescence, a charge of $1 \times 10^{-16} \mathrm{C}$ would be needed on half of the cloud droplets. Assuming a cloud droplet concentration of $100 \mathrm{~cm}^{-3}$ this would require a charge delivery rate of $10 \mathrm{nCm}^{-3}$. With the typical RPA airspeed assumed of $v=30 \mathrm{~m} \mathrm{~s}^{-1}$, a charge delivery system would therefore need to provide $0.3 \mu \mathrm{A} \mathrm{m}^{-2}$ which is similar to that estimated above.

Releasing unipolar charge will also affect the electric potential of the aircraft compared with the local environmental potential, as the aircraft will develop an opposite charge equal in magnitude to the charge released. The charging rate of the aircraft can be estimated as

$$
\frac{d V}{d t}=\frac{I_{c}}{C}
$$

where $d V / d t$ is the rate of change of the potential of the aircraft and $C$ is the aircraft's capacitance. If the aircraft is considered as an isolated spherical capacitor of radius $1 \mathrm{~m}, C \sim 100 \mathrm{pF}$, and the associated $d V / d t$ for $I_{c}=10 \mathrm{nA}$ will be $90 \mathrm{~V} \mathrm{~s}^{-1}$. This is likely to overestimate the charging rate, as any loss of charge from the aircraft is neglected. This could occur by collision or attraction of atmospheric space charge, which would act to reduce the charging rate.

The limitations on unipolar charge release implied by Eq. (5) are important, as if the charge emission continues indefinitely, the electric field at the surface of the aircraft will ultimately become dangerously large, leading to systems failure through electrostatic discharge damage, and possible loss of the aircraft. (In the case of ion thrusters for spacecraft, neutralizers are specifically included to avoid this; e.g., Kent et al. 2005.) This risk can be reduced by approximately balanced emission of positive and negative charge, as then the aircraft charging will be less rapid, determined by the difference in the emission currents which is likely to be smaller than their absolute magnitude. A discharge wick, widely used on traditional aircraft, provides another possibility. A consequence of bipolar emission is, however, that the loss of corona ions by recombination will be increased.

A controllable RPA charge emission system developed is now described (section 3 ) able to provide up to $\pm 5 \mu \mathrm{A}$ of corona current, followed by considerations associated with its integration into the aircraft (section 4). Flight tests evaluating the meteorological and electrical aspects are described in section 5 .

\section{Aircraft charge emitters}

The charge emitters emit corona ions from a carbon fiber brush, raised to a high voltage. Two separate unipolar emitters are used, controllable to release positive and negative charge independently. These were designed to have a physical form $(130 \mathrm{~mm} \times 40 \mathrm{~mm} \times 40 \mathrm{~mm})$ and mass $(100 \mathrm{~g})$ suitable for small aircraft, and to operate from a $12 \mathrm{~V}$ power supply. Each emitter's current varies with the operating voltage chosen, 


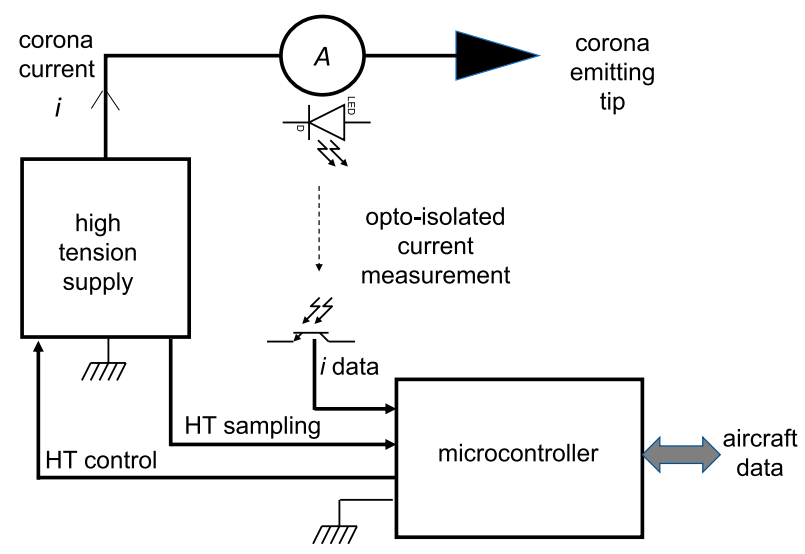

FIG. 2. Charge emitter block diagram. A miniature high-tension generator (EMCO A-series, A60P-5 for positive, A60N-5 for negative) is used to generate sufficient voltage to generate corona at the emitting tip. The HT voltage is set by the microcontroller, using a 12-bit DAC to control a MOSFET-based op-amp regulator circuit. The HT voltage is sampled by the same microcontroller using a 1000:1 resistive divider potential divider, at 10-bit resolution. The corona current flowing to the tip is sampled on the highvoltage side (using an AD8293G160 instrumentation amplifier with gain of 160) and digitized at 10-bit resolution by a further microcontroller, with the values transmitted serial over an optically isolated link to the main microcontroller. Control of the emitters is achieved by data exchange with the aircraft systems, which also provide data telemetry to the surface.

which is remotely controllable through the aircraft telemetry (Fig. 2). The currents supplied to the emitting tips can be monitored, which allows the positive and negative currents to be balanced, to minimize the aircraft charging hazard. Because the current measurement has to be obtained at the emission (high voltage) part of the corona emitter circuit, an isolated system is required to provide the measurement at safe voltages for the aircraft's data telemetry. Communication between the aircraft system and the emitters is therefore required in two directions, from the aircraft to the emitter to set the high tension operating voltage (which is also confirmed by a signal in the opposite direction), and from the emitter to the aircraft to report the corona current. This information is recorded by the aircraft data system.

In each charge emitter, the operating high voltage is requested by the aircraft's datalogger, over a USB-UART serial link, and the resulting output current monitored. Within each emitter, a microcontroller acts as the main control and communication link between the aircraft and the device, providing control of the high-voltage module and monitoring of the output voltage, while another internal UART serial link communicates over an optical isolator with the current sensing section.

The ion production is determined by the current flowing from the high-voltage module through the discharge brush into the surrounding environment. This current is monitored by measuring the voltage drop across a series resistor between the module output and emitting tip. Since the current sensing circuit is elevated to the potential of the high-voltage output of

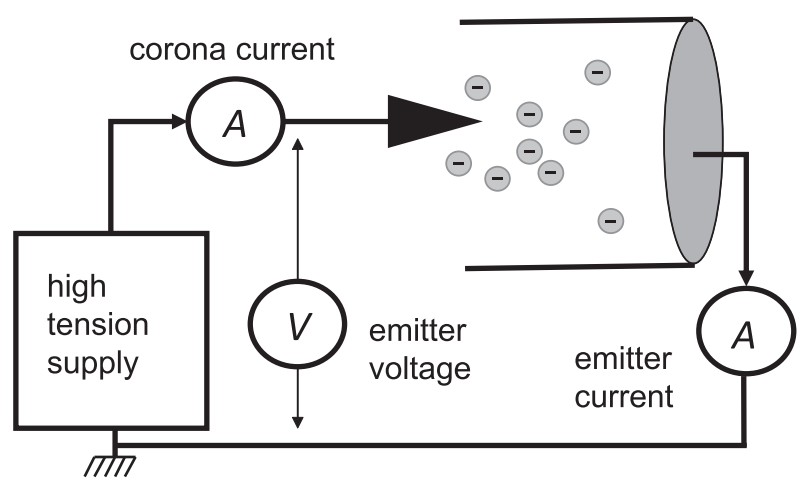

FIG. 3. Conceptual diagram of the test system for a single charge emitter. A controlled high voltage is applied to an emitting tip (black arrow), and the corona current determined using the isolated measurement system of Fig. 2. The current emitted is also sampled at a nearby detection plate (shown by the black ellipse). To achieve current balancing, a second opposite polarity emitter can be applied to the other side of the detection plate.

the module, the measurements are returned through an optical link (e.g., Harrison 2002; Aplin et al. 2008), with its supply galvanically isolated from the low voltage section of the board. A chain of three transformers (type PT6) with their secondaries in series is used to provide a total isolation of $9 \mathrm{kV}$, using a square wave oscillator drive, as shown in Harrison (1997).

The actual output currents from the charge emitters were characterized using the experimental arrangement summarized in Fig. 3. For this, the emitting tip (a carbon fiber discharge brush) was mounted on a PTFE stand-off, within a large grounded diecast box. The discharge brush was pointed at a brass detector plate connected to a transresistance converter (using a $1 \mathrm{M} \Omega$ feedback resistance) circuit, to measure the corona ion current flowing to the brass plate at the local ground potential. The detector plate was mounted centrally within the box, to allow symmetrical operation of the two emitters either side of the plate. Through this arrangement, balancing of the output currents from both emitters was achieved by independently adjusting their operating high-tension (HT) voltages, until the opposite currents were sufficiently similar that no net plate current was measured.

Figure 4a shows the current measured by the detection plate as the operating voltage of the corona emitters was varied. The onset threshold for corona emission is also related to the precise emitter tip shape, but was found to be around $1200 \mathrm{~V}$ for the negative emitter and $2300 \mathrm{~V}$ for the positive emitter. The absolute current measured by the detector plate depended on the geometry, as varying the distance between the discharge wick and the plate changed the effectiveness of ion capture and the associated detector plate current. Figure $4 \mathrm{~b}$ shows the operation of the onboard isolated corona current measurement circuit when the corona current was varied, by changing the HT voltage. The linear relationship found between the corona current and HT voltage demonstrates that, through adjusting the HT voltage, the emission current can be altered in flight. 
(a)

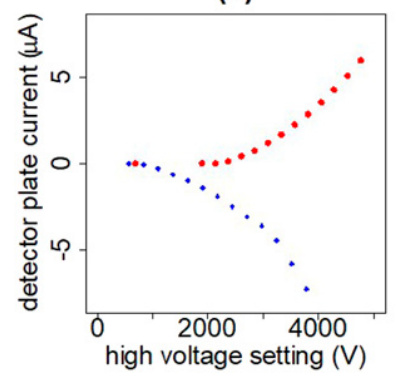

(b)

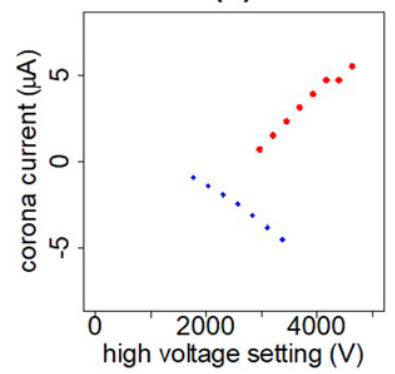

FIG. 4. Tests on the corona emitters. (a) Ion current measured at the detector plate of Fig. 3 as the high-voltage setting (HT voltage) on the corona tip was varied, in separate experiments. (b) Relationship between current measured by the onboard corona current measurement circuit and HT voltage. (In both cases, red circles are for the positive emitter and blue crosses for the negative emitter.)

\section{Aircraft science equipment integration}

The RPA platform chosen for this work is the commercially available Skywalker X8 fixed wing aircraft. Use of a standard platform allows for possible scaling up to a fleet of aircraft. The $\mathrm{X} 8$ is capable of the long-range operations required to fly into clouds, including an ability to climb to altitudes of $3 \mathrm{~km}$. It is a flying wing design made of expanded polyolefin foam, with a single folding propeller in a pusher configuration. It has a wingspan of $2.1 \mathrm{~m}$ and maximum takeoff mass of $5 \mathrm{~kg}$, with capacity to carry scientific equipment in a small payload bay at the front of the aircraft. The "pusher" configuration allows the science instrumentation to be located far from the propellers and noise generating components, reducing electrical interference on the measurements. In use, the RPA is flown autonomously using a Pixhawk 2.1 Cube autopilot with Arduplane software (V3.9.6), propelled by a Cobra $3520550 \mathrm{Kv}$ motor with Aeronaut 13 in. $(33 \mathrm{~cm}) \times 8$ propellors and a FrSky Neuron 60 Electronic Speed Controller. UHF control links are made at $868 \mathrm{MHz}$. Separate 3000 and $4000 \mathrm{~mA} \mathrm{~h} \mathrm{LiPo} \mathrm{batteries} \mathrm{are} \mathrm{used}$ to power the systems and propulsion motor, respectively.

The locations of the various science sensors installed on the aircraft are shown in Fig. 5. As the RPA is designed to fly within, and sample, cloud properties, it has been instrumented with temperature (RSPRO 2.4-mm-diameter bead thermistor) and RH sensors (Honeywell HIH-4000), and an optical cloud sensor (OCS) (Harrison and Nicoll 2014) located in the front of the aircraft, pointing downward to minimize water ingress and to provide shielding from solar radiation. Atmospheric space charge density sensors [with both linear (Nicoll 2013) and logarithmic (Harrison et al. 2017) responses] are also located in the front of each wing to monitor the charge environment surrounding the aircraft. Data from all the science sensors are logged at $1 \mathrm{~Hz}$ through a custom-made datalogging board based on a TinyDuino (an ATMEGA328-based device) as the main processor, carrying its own GPS and data storage.

Mounting positions for the corona emitters are also shown in Fig. 5, on the underside of the wings, approximately $20 \mathrm{~cm}$ from the propellor, facing backward. The positive corona emitter is

located on the left wing, the negative emitter on the right wing. This positioning ensures that the corona ions are emitted into the turbulent flow behind the aircraft, helping to disperse the ions and ensuring they do not return to the aircraft, which would modify its charge. The corona emitters can be switched independently to provide positive, negative, or bipolar ion emission, using optically isolated switches activated by the pilot through the remote control (RC).

\section{Flight tests of aircraft instrumentation}

Separate series of flight tests were undertaken to evaluate the flight endurance and payload capability, meteorological measurements, and charge emission. Calibration information on the sensors is provided in the appendixes.

\section{a. Aircraft aspects}

To examine the flight capabilities of the extensively instrumented Skywalker airframe, test flights were conducted at the Pallas Atmosphere-Ecosystem Supersite, in sub-Arctic Finland during the Pallas Cloud Experiment (PaCE 2019) (latitude $68.01^{\circ} \mathrm{N}$, longitude $24.14^{\circ} \mathrm{E}$ ) during September 2019 . This site had a designated temporary dangerous area (EFD527), permitting flights to a ceiling of $2 \mathrm{~km}$ above mean sea level (MSL). Table 1 summarizes all the RPA flights undertaken, including details of the eleven flights conducted at Pallas. The longest endurance flight path is shown in Fig. 6.

The maximum altitude reached in this flight was $2000 \mathrm{~m}$ MSL in a flight duration of $20 \mathrm{~min} 45 \mathrm{~s}$. This consisted of an $11 \mathrm{~min}$ climb at a $10^{\circ}$ angle to $2000 \mathrm{~m}$, followed by a 9 min glide to landing. The principal battery usage occurred during the climb, requiring a mean current of $16 \mathrm{~A}$ compared with $0.2 \mathrm{~A}$ during the descent. Over the entire flight, the total charge drawn from the propulsion battery was $3850 \mathrm{~mA} \mathrm{~h}$, of the $4000 \mathrm{~mA}$ h nominally available.

\section{b. Meteorological sensors}

The meteorological measurements made by the X8 RPA during flight were compared with nearby meteorological measurements made using a balloon-carried instrument package, employing an RS41 radiosonde augmented with additional science sensors.

The balloon payload consisted of a standard Vaisala RS41 radiosonde with an OCS (Harrison and Nicoll 2014) and charge sensor (Nicoll 2013) attached, of identical design to those on the aircraft. The add-on sensors were housed in a 3D printed enclosure. This enclosure had fixing spikes printed to grip into the RS41's polystyrene shell, firmly securing the add-on sensors with a tensioned cable tie. Data from the sensors were relayed through the RS41's telemetry system using the ozone sensor (OIF411) port, following Harrison et al. (2012). The sensor data were interleaved with the RS41's data stream and recorded by the ground station. The additional data packets were synchronized with the standard meteorological data after the ascent. The RS41 carried standard temperature and humidity sensors, having a quoted accuracy of $\pm 0.01^{\circ} \mathrm{C}$ and $\pm 0.1 \%$, respectively (Vaisala 2018).

An intense observation period was undertaken at the Pallas site on 27 September 2019 to compare the balloon and aircraft 
(a)

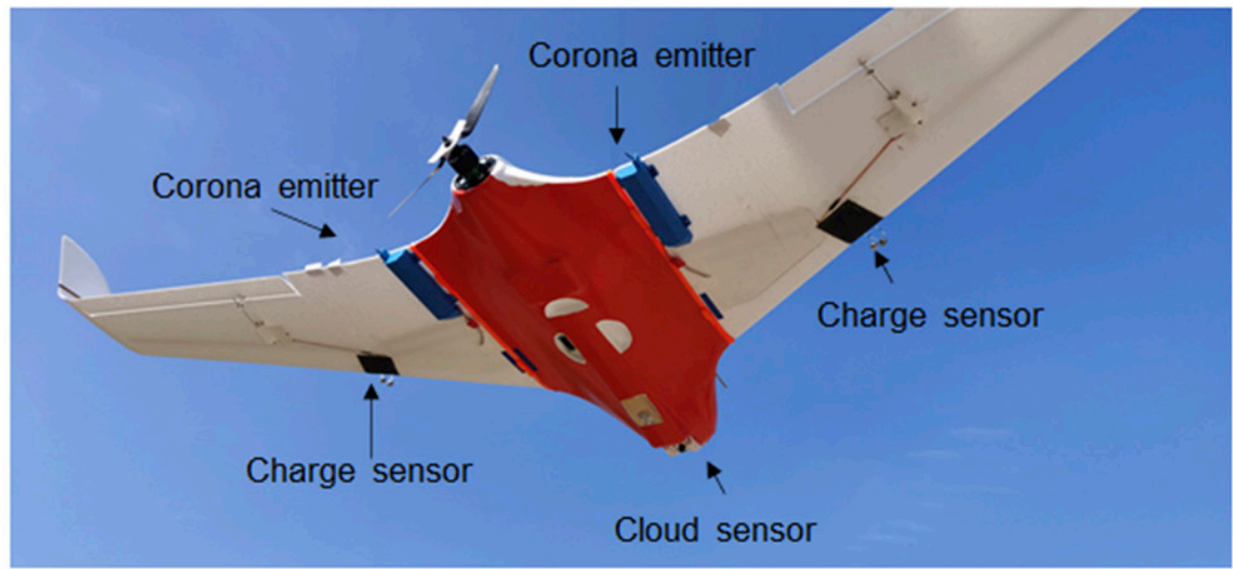

(b)

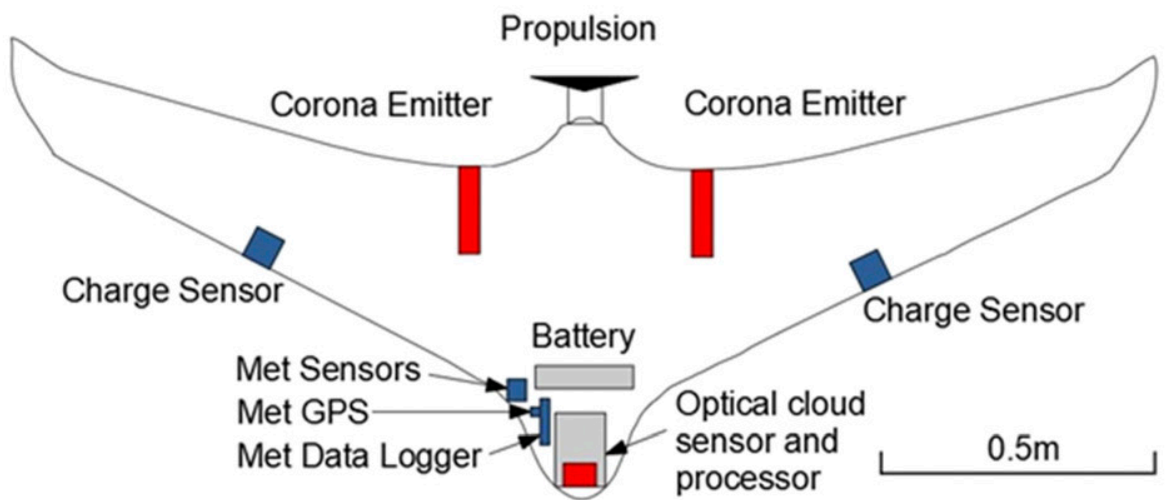

(c)
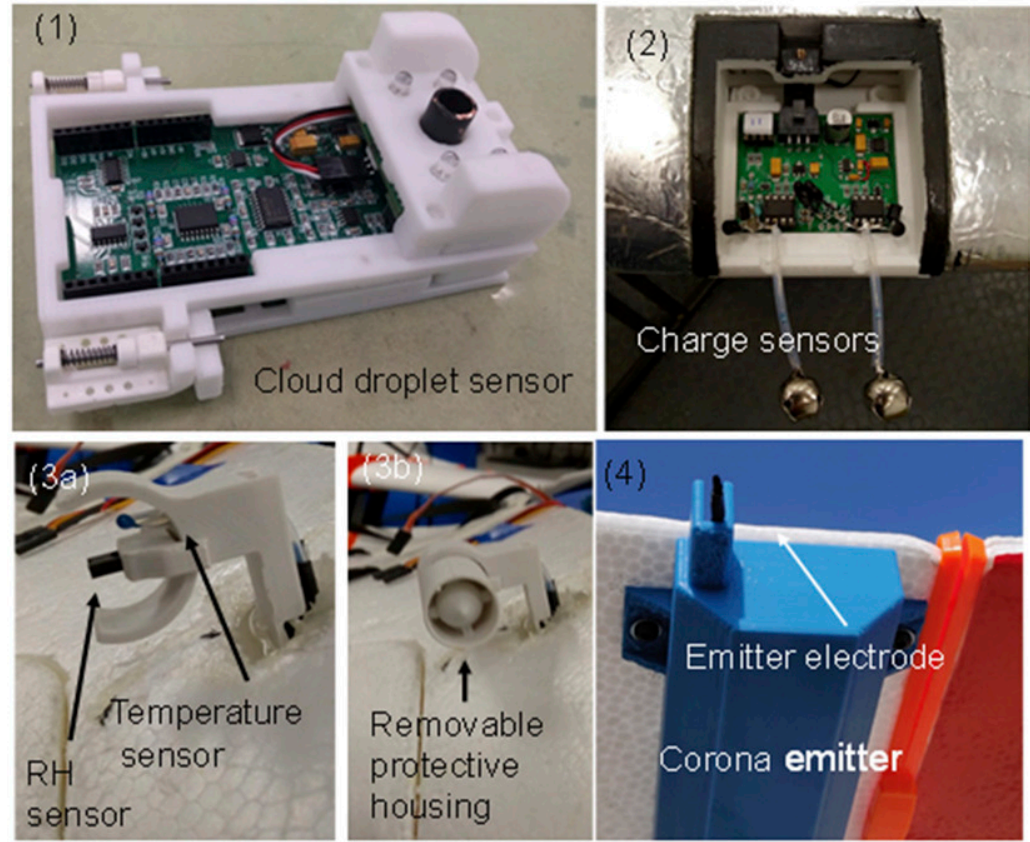

FIG. 5. (a) Instrumented Skywalker X8 aircraft in flight, with instrumentation labeled. (b) Arrangement of sensors and systems on the X8 airframe (not to scale). (c) Detail of the individual science instruments: (c1) optical cloud sensor, (c2) charge sensors, (c3a) thermodynamic (temperature and RH) sensors, (c3b) removable protective housing for thermodynamic sensors, and (c4) corona emitter electrode. 
TABLE 1. Summary of instrumented flights conducted.

\begin{tabular}{|c|c|c|c|c|c|}
\hline Date & Local time & Flight duration (min) & Max altitude (m) & Location & In-cloud duration ( $\mathrm{min})$ \\
\hline 24 Sep 2019 & 1130 & 15 & 1000 & Pallas & 0 \\
\hline 24 Sep 2019 & 1630 & 15 & 1450 & Pallas & 0 \\
\hline $25 \operatorname{Sep} 2019$ & 1415 & 16 & 1450 & Pallas & 1 \\
\hline 25 Sep 2019 & 1530 & 17 & 1450 & Pallas & 1 \\
\hline 26 Sep 2019 & 1210 & 22 & 1575 & Pallas & 5 \\
\hline 27 Sep 2019 & 0915 & 17 & 1950 & Pallas & 5 \\
\hline 27 Sep 2019 & 1045 & 21 & 2050 & Pallas & 1 \\
\hline 28 Sep 2019 & 0920 & 17 & 1150 & Pallas & 0 \\
\hline 28 Sep 2019 & 1210 & 15 & 1400 & Pallas & 1 \\
\hline 28 Sep 2019 & 1250 & 20 & 1315 & Pallas & 2 \\
\hline 1 Oct 2019 & 0925 & 18 & 815 & Pallas & 0 \\
\hline 29 Nov 2019 & 1345 & 22 & 100 & Bristol & 0 \\
\hline 29 Nov 2019 & 1455 & 17 & 100 & Bristol & 0 \\
\hline
\end{tabular}

systems. For this, a fully instrumented RPA flight into a thin stratiform cloud was made, followed by an RS41 special sensor balloon launch to provide reference data. The radiosonde and aircraft data obtained are now compared.

Figures $7 \mathrm{a}$ and $7 \mathrm{~b}$ show the standard thermodynamic meteorological quantities from the RS41 radiosonde in black, and the $\mathrm{X} 8$ aircraft in red. From the temperature and $\mathrm{RH}$ data a cloud layer $100 \mathrm{~m}$ thick at approximately $1700 \mathrm{~m}$ is apparent. The cloud top is capped with a $5^{\circ} \mathrm{C}$ inversion at $1800 \mathrm{~m}$. Figure $7 \mathrm{a}$ demonstrates $\mathrm{a}-2^{\circ} \mathrm{C}$ cold bias of the temperature sensor on the X8 when compared to the RS41 temperature sensor, which can be corrected in future flights. The X8's RH sensor tracked the RS41 sensor closely, except in the cloud-top region at $1800 \mathrm{~m}$ where it lagged the RS41, taking longer to adjust to the cloud features. As the radiosonde and the X8 each encountered the cloud layer at different speeds, displaced in time, their lag times cannot be uniquely identified. The response time of the RS41's humidity sensor is given by the manufacturer (Vaisala 2018) as less than $0.3 \mathrm{~s}$ at $20^{\circ} \mathrm{C}$ and less than $10 \mathrm{~s}$ at $-40^{\circ} \mathrm{C}$.

\section{(a) Pallas GPS Flight Path}

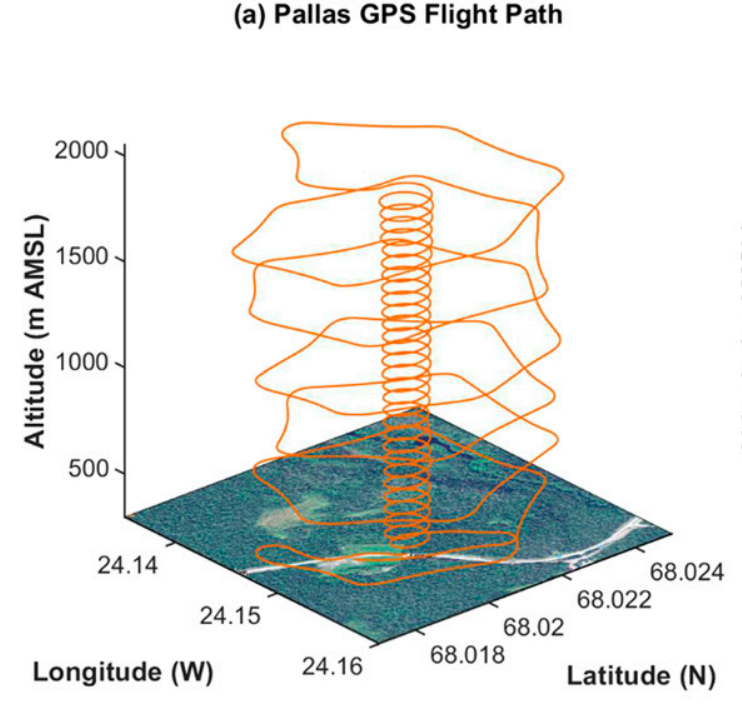

Figure $7 \mathrm{c}$ shows the charge density from the port wingmounted charge sensor, plotted alongside the charge density inferred from the charge sensor data from the radiosonde. The charge was calculated following Nicoll and Harrison (2016). In the cloud at $1700 \mathrm{~m}$ the wing mounted charge sensor detected a maximum positive charge density of approximately $50 \mathrm{pC} \mathrm{m}^{-3}$; the radiosonde detected a similar maximum positive charge density of $60 \mathrm{pC} \mathrm{m}^{-3}$. Such extensive layer clouds often show charging associated with the upper and lower cloud boundaries (Nicoll and Harrison 2016). The two traces demonstrate similar charge profiles from two different measurement platforms which encountered the same cloud environment. The greater variability apparent in the $\mathrm{X} 8$ profiles may be due to additional electrical noise from the aircraft systems, or naturally generated lateral charge variations.

Finally, cloud droplet number concentrations derived from the OCS on the two measurement platforms are compared in Fig. 7d. Both OCSs on the radiosonde and X8 aircraft recorded peak droplet concentrations of $150 \mathrm{~cm}^{-3}$ within the cloud

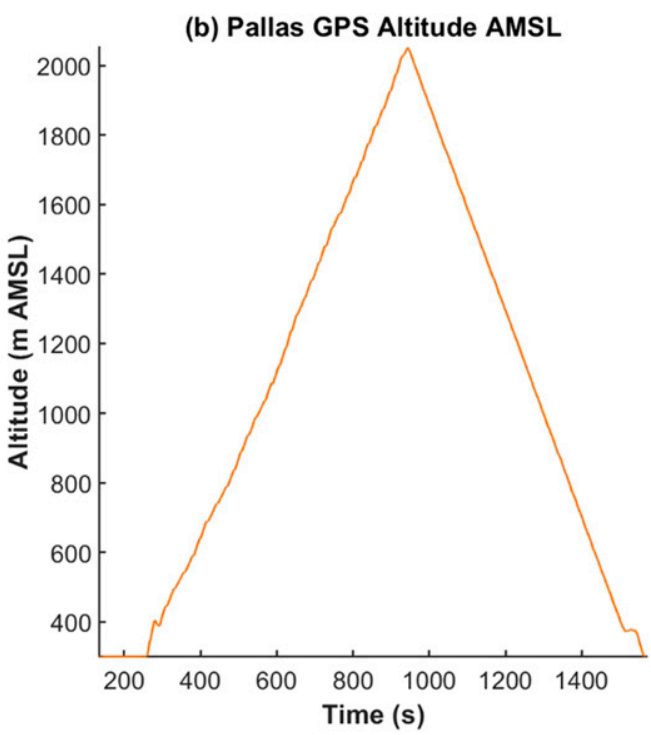

FIG. 6. (a) Flight path and (b) altitude reached by the X8 during the longest endurance flight undertaken at Pallas at 1045 LT 27 Sep 2019. 
X8 flight on 27/09/2019 ASCENT at 1009UT (RS41 at 1045UT)
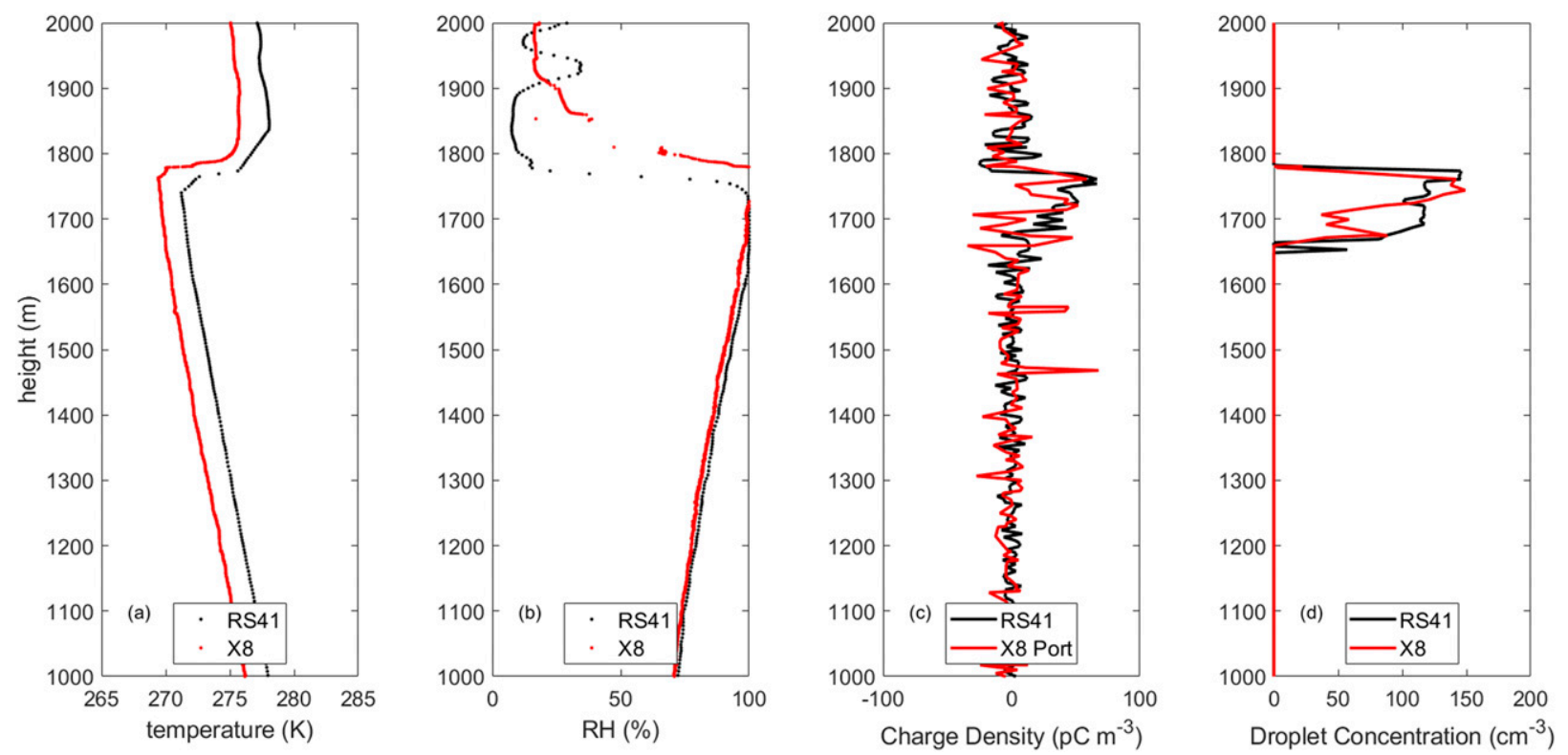

FIG. 7. Comparison of radiosonde (RS41, released at 1045 UTC) and aircraft (X8, flown at 1009 UTC) profiles on 27 Sep 2019. These are for (a) temperature, (b) relative humidity, (c) charge density, found from the portside charge sensor on the X8, and (d) droplet concentration, using a nose-mounted optical cloud sensor on the X8. (X8 data are in red and RS41 data in black).

layer. (The method of calculation of the droplet concentration from the raw sensor output is described in appendix B.)

In summary, the instrumented $\mathrm{X} 8$ airframe can provide thermodynamic, electrical, and optical measurements in cloud, at up to $2000 \mathrm{~m}$ above the surface.

\section{c. Charge emission aspects}

Further trials were undertaken to test the operation of the corona emitters in flight and quantify the emitted charge during low level flying over a surface electric field instrument. Positive charge emission from the aircraft would result in a positive electric field perturbation beneath and a negative field perturbation for negative charge emission. Flights were performed at the University of Bristol's Fenswood Farm, Long Ashton, United Kingdom $\left(51.423^{\circ} \mathrm{N}, 2.671^{\circ} \mathrm{W}\right)$. The site is a large flat agricultural pasture without obstacles. Two flights were conducted on 29 November 2019, under fair weather conditions with clear skies and no appreciable local charge generation from meteorological processes. (Details of these further flights are also provided in Table 1.) Detection of the aircraft's charge emission was made using a Chubb JCI131 electric field mill (EFM), to measure the vertical electric field at the surface. The EFM was mounted on a 3-m-high vertical mast, separately calibrated to correct for the electric field distortion due to the presence of the earthed mast. The measurement range of the EFM was $\pm 2 \mathrm{kV} \mathrm{m}^{-1}$ with a resolution of $0.1 \mathrm{~V} \mathrm{~m}^{-1}$, and values logged at $1 \mathrm{~Hz}$.

To detect charge emission from the aircraft, a stable and reliable pattern of corona emission was required, which was achieved through conducting flight operations automatically to maintain consistent flight paths. Each mission was divided into three separate operational stages. Initially, a rectangular flight path conducted at $50 \mathrm{~m}$ altitude was used to ensure that the aircraft was operating correctly. This was followed by level flight operations above the EFM. Finally, a circular, unlimited loiter pattern was made above the EFM. The mean loiter speed of the aircraft was $19 \mathrm{~m} \mathrm{~s}^{-1}$ and the total flight time was $17 \mathrm{~min}$.

Figure $8 \mathrm{a}$ shows details of the flight path, demonstrating the level flight operation legs, and the indefinite circular loiter pattern. The circular loiters were conducted at 15 and $20 \mathrm{~m}$ above ground level, with a $50 \mathrm{~m}$ radius. Each loiter was planned to position the edge of the flying circle above the EFM.

Figure 9 shows the surface electric field $E$ time series during the X8's second flight. Markers show when either corona emitter was switched on and off. Whenever one emitter was activated on the aircraft, a transient change in $E$ was detected beneath. For positive corona, $E$ increased and for negative corona events $E$ decreased. When, however, both emitters were activated there was a negligible change in $E$, which indicates that the opposite polarities act to cancel the point charge, as perceived by the EFM.

The densest region of charge emitted by the aircraft can be considered quantitatively to be represented by an equivalent point charge above the EFM. For a point charge $Q$, the electric field $E$ induced by the point charge at distance $r$ is given by

$$
E=\frac{Q}{4 \pi \varepsilon_{0} r^{2}},
$$

where $\varepsilon_{0}$ is the permittivity of free space and $r$ becomes the height of the aircraft above the EFM. By using a smoothing spline (with a unit smoothing parameter for a piecewise cubic 


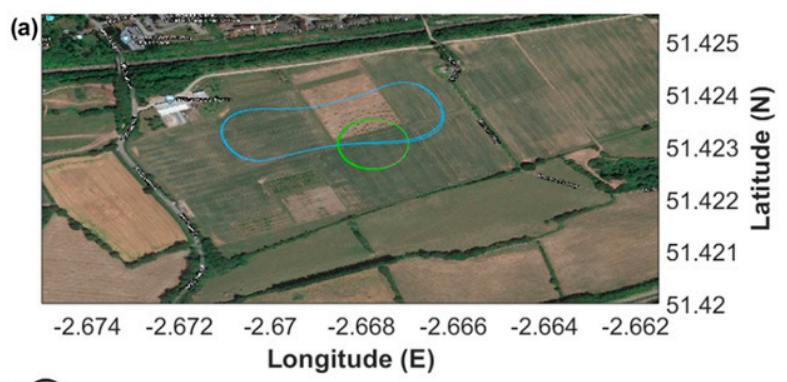

(b)

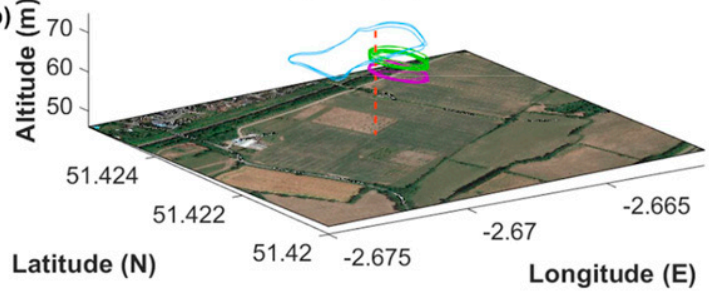

FIG. 8. (a) Bird's-eye view of the flight path of the aircraft showing the square path (light blue) and circular loiter path (green and purple). (b) Three-dimensional view of the flight path with the square pattern at $20 \mathrm{~m}$ altitude (light blue), $50 \mathrm{~m}$ radius loiter at $20 \mathrm{~m}$ altitude (green), and the $50 \mathrm{~m}$ radius loiter at $15 \mathrm{~m}$ altitude (purple), centered on the surface field mill location (dashed red vertical line).

spline interpolation), to detrend the electric field time series to retain only the transient changes (as shown in Fig. 10), the emitted charge from the aircraft can be calculated from Eq. (6). Using this methodology, the mean of the inferred point charges for the five positive and five negative transients observed in Fig. 10 was found to be $0.43 \mu \mathrm{C}$ when the positive emitter was activated, and $-0.35 \mu \mathrm{C}$ when the negative emitter was activated. The small magnitude difference is likely to be associated with the different magnitudes of operating currents from the two emitters (calculated to be 5.3 and $-2.8 \mu \mathrm{A}$ for the positive and negative emitters, respectively). The detected charge was evidently much less $(90 \%)$ than the instantaneous charge emitted. For an emitter current of $\sim 5 \mu \mathrm{A}$, a charge of $\sim 5 \mu \mathrm{C}$ would be expected to be observed when the RPA passed directly over the electric field mill. These measurements, when combined with the findings in Figs. 3 and 4, indicate that most of the released ionic charge is rapidly dispersed in the atmosphere, to be removed through ion recombination or attachment to boundary layer aerosol (Harrison and Carslaw 2003). The charge removal to droplets in a cloud situation can be expected to be similar, with the mixing processes associated with the turbulent air behind the aircraft acting to spread the air ions released.

\section{d. Summary}

Taken together, the evaluations undertaken in sections 5a-c show that the objectives stated in the opening paragraph have been addressed and, specifically, that the instrumented aircraft is able to

1) carry scientific payload to cloud-level altitudes, with an endurance of $10 \mathrm{~min}$,

2) provide thermodynamic meteorological profile information,

3) locate cloud regions through the combination of a rapid time response relative humidity sensor and an optical cloud sensor using backscattered light from the water droplets, and

4) deliver charge in a controllable and monitored manner, of either, or both polarities.

Further, the commercial airframe employed and the standard devices and components used in construction of the instrumentation make the production of multiple aircraft readily achievable, to increase the volume of cloud which can be intermittently sampled or continuously interacted with.

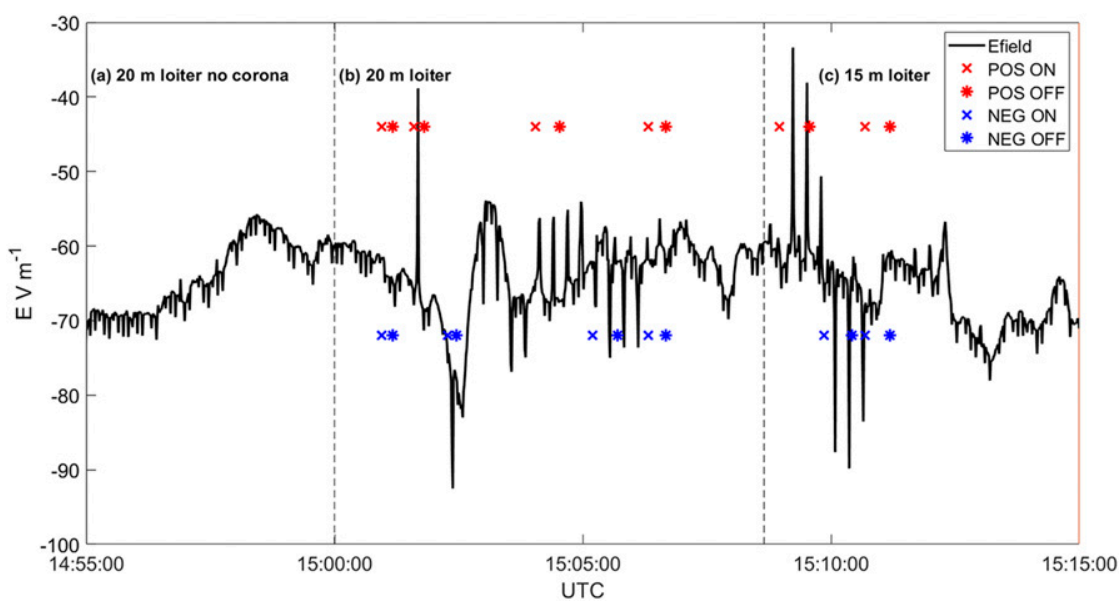

FIG. 9. Time series of electric field $(E)$ from the Chubb JCI131 electric field mill at Fenswood Farm on 29 Nov 2019, with the instrumented X8 aircraft flying overhead in different flight patterns. The flight patterns were (a) loiter but no corona emitters activated and (b) 20 and (c) $15 \mathrm{~m}$ radius loiter with corona emitters cycled. Crosses and asterisks mark when the charge emission was switched on and off, respectively, with blue and red used to indicate the positive and negative charge emitter, respectively. 


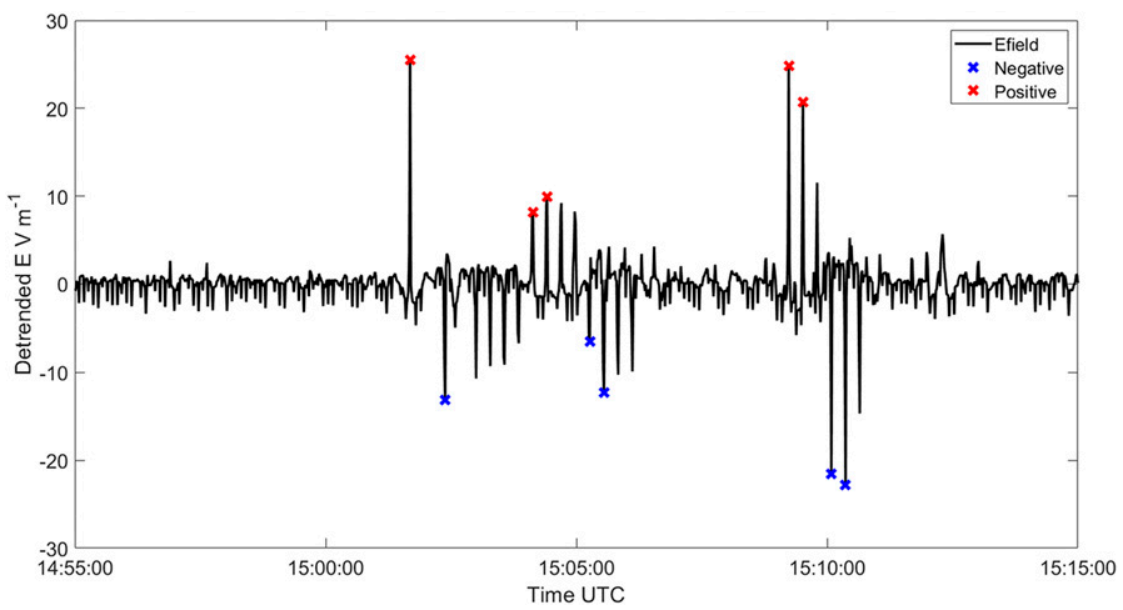

FIG. 10. Detrended electric field $(E)$ from the Chubb JCI131 electric field mill at Fenswood Farm on 29 Nov 2019, from Fig. 9. (Red and blue crosses identify electric field transients from which the charge released was calculated.)

\section{Conclusions}

The instrumented RPA platform described here generates a new capability for cloud and aerosol investigations, and for assessing effects on their electrical behavior following charge release. It successfully provided thermodynamic, optical, and electrical properties of clouds at heights up to $2 \mathrm{~km}$, allowing most boundary layer clouds to be accessed and studied, as well as mists, fogs, and aerosol plumes. The novel combination of a controllable bipolar charge delivery system with integrated optical sensors allows cloudy regions to be identified and targeted remotely or autonomously. Future use of electric aircraft by ionic propulsion, or the neutralization of highly charged particle clouds presenting electrostatic hazards, illustrate further environmental applications which may benefit from targeted charge release capability.

Atmospheric charge release has established biological and agricultural applications and may ultimately have a new use in geoengineering through providing cloud droplet charging. This work shows that charge delivery into large atmospheric volumes can be effectively achieved by small electrically powered aircraft. As the charge is only emitted from a single point, further work is needed to establish the active area over which the charge is distributed. To achieve a greater effective release area, some alternative approaches could be considered. Fitting a set of emitters on a larger airframe provides one possibility; another, with greater volume coverage, would be through implementing an aircraft "swarm," with multiple aircraft following the same flight pattern and simultaneously releasing charge across a range of altitudes.

Investigating geoengineering applications, whatever their ultimate societal value, is an increasingly urgent priority which is directly addressed by this technology. For this new application, electrically powered robotic aircraft provide adaptable delivery platforms without combustion products, and the charge released itself leaves no environmentally damaging residues.

Acknowledgments. This material is based on work supported by the National Center of Meteorology, Abu Dhabi, UAE, under the UAE Research Program for Rain Enhancement Science (UAEREP). KAN acknowledges an Independent Research Fellowship funded by the Natural Environment Research Council (NERC) (NE/L011514/1 and NE/L011514/2). Stefan Chindea's involvement was supported by the NERC Grant NE/N012070/1. Sam Hyams, James Male, and Freddie Sherratt made valuable contributions to building and flying the aircraft. The meteorological sensor characterization was undertaken by NERC SCENARIO summer students Heather Jones and Charlie Bell. Test flights in Finland were made during the 2019 Aerosol, Clouds and Trace Gases Research Infrastructure (ACTRIS) project in Pallas coordinated by the Finnish Meteorological Institute, a cofunded Institute of UAEREP. (ACTRIS-2 received funding from the European Union's Horizon 2020 research and innovation program under Grant Agreement 654109; ACTRIS PPP is supported by the European Commission under the Horizon 2020-Research and Innovation Framework Programme, H2020-INFRADEV-20162017, Grant Agreement: 739530.) The University of Bristol provided access to Fenswood Farm for flight tests.

Data availability statement. Data from the instrument tests are available from the corresponding author.

\section{APPENDIX A}

\section{Meteorological Sensor Calibration}

This section discusses the meteorological sensor package carried on the aircraft, and the associated calibration. The sensors consisted of a bead thermistor and an integrated relative humidity sensor (Honeywell HIH4000).

The RSPRO $10 \mathrm{k} \Omega$ bead thermistor (type RS 151-237, $2.4 \mathrm{~mm}$ diameter) was connected to a $10 \mathrm{k} \Omega$ precision resistor to form a half-bridge, i.e., a potential divider from a regulated supply, giving a voltage output $V_{\text {THS }}$. The thermistor was calibrated against a standard platinum resistance thermometer 


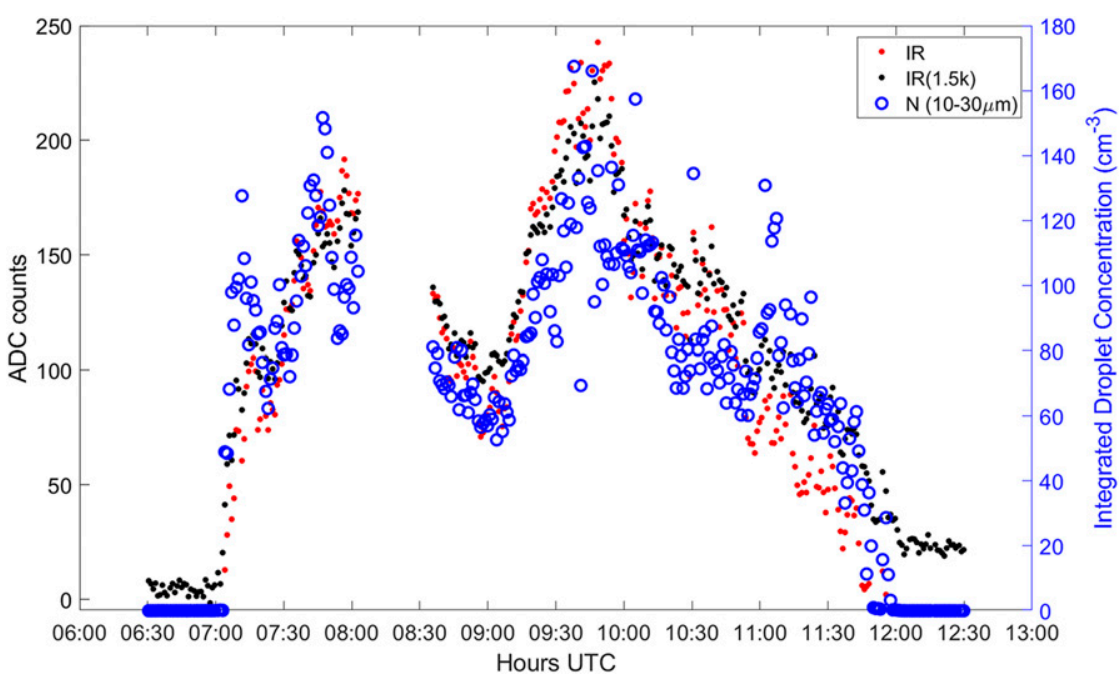

FIG. B1. Comparison of OCS and LOAC devices. Time series showing the analog-to-digital converter (ADC) voltage counts from the two IR cloud sensor channels (black and red) and the integrated droplet count (blue) across the 10-30- $\mu$ m-diameter bins from the LOAC, between 0600 and 1300 UTC 15 Feb 2019.

(PRT), $T_{\mathrm{PRT}}$ over a temperature range of $-20^{\circ}$ to $40^{\circ} \mathrm{C}$ in an environmental chamber. Through this, the thermistor bridge was found to have a first-order linear response of

$$
T_{\text {PRT }}=20.397 V_{\text {THS }}-25.960,
$$

for $T_{\mathrm{PRT}}$ in Celsius and $V_{\mathrm{THS}}$ in volts.

The HIH4000 humidity sensor was calibrated by placing it in an environmental chamber at $20^{\circ} \mathrm{C}$. The $\mathrm{HIH} 4000$ s voltage output $V_{\mathrm{RH}}$ was calibrated against a Michell dewpoint sensor in the chamber. The relative humidity $(\mathrm{RH})$ within the chamber was increased from $30 \%$ to $100 \%$ in $5 \%$ steps. A first-order response was found between the HIH4000s voltage output $V_{\mathrm{RH}}$ and the $\mathrm{RH}$ measured from the dewpoint hygrometer $\mathrm{RH}_{D}$ of

$$
\mathrm{RH}_{D}=30.547 V_{\mathrm{RH}}-24.607,
$$

for $\mathrm{RH}$ measured in percent and $V_{\mathrm{RH}}$ in volts.

\section{APPENDIX B}

\section{Cloud Droplet Sensor Calibration}

The calibration of the optical cloud sensor (OCS) is presented here. Its operation is described in Harrison and Nicoll (2014), but for this application it was extended to provide four channels. It consists of four high-power light-emitting diodes (LEDs) in an open-path arrangement, with their backscattered light sensed by a photodiode mounted behind the LEDs. Two of the four LEDs are infrared devices (peak emitting wavelength: $850 \mathrm{~nm})$, one cyan $(505 \mathrm{~nm})$, and one orange $(590 \mathrm{~nm})$, each of which is driven by a square wave at a unique frequency in the range between 1.1 and $1.5 \mathrm{kHz}$. Any cloud droplets in the optical path from the LEDs will backscatter the modulated light, some of which is received by the photodiode. The photodiode signal is bandpass filtered to eliminate fluctuating daylight, so that only the modulated backscattered signal from the cloud droplets is retained. The independent square wave signals driving the LEDs are also used for phase-sensitive detection of the individual channels, to allow the photodiode signal to be decomposed into separate responses associated with each LED. Each of the four recovered signals is separately low-pass filtered and amplified to yield a DC voltage output which is proportional to the backscatter, from which the size and concentration of water droplets are found by calibration.

The OCS was calibrated against a light optical aerosol counter (LOAC), described in Renard et al. (2015). The LOAC measures the concentrations of aerosol, dust, and water droplets in the size range 0.1 to $50 \mu \mathrm{m}$. It operates by pumping air through a laser chamber, with photodiodes mounted at $12^{\circ}$ and $60^{\circ}$ from the laser path to receive light scattered by droplets and particles. The number of forward scattered pulses received at each photodiode gives the concentration. By comparing the nature of the scattered light at each photodiode, information about the size and type of particle, e.g., carbon, mineral, ice, or water can also be recovered. The LOAC returns concentrations in 17 size bins at $1 \mathrm{~min}$ time resolution.

In a calibration experiment, two OCS devices were mounted alongside the LOAC above the surface on a $2.5 \mathrm{~m}$ mast, approximately $500 \mathrm{~m}$ from the River Thames in a large flat arable field on the University of Reading's Sonning farm $\left(51.47^{\circ} \mathrm{N}\right.$, $\left.0.89^{\circ} \mathrm{W}\right)$. This site experiences fog and river mists. The OCS devices were logged by an Arduino microcontroller operating in a similar manner to that used on the aircraft logging system. This arrangement was deployed in January 2019 for two months. During 14, 15, and 17 February 2019, fog events lasting several hours occurred at the site.

Figure B1 shows data from a fog event on 15 February 2019. The fog formed at approximately 0700 UTC and dissipated at 


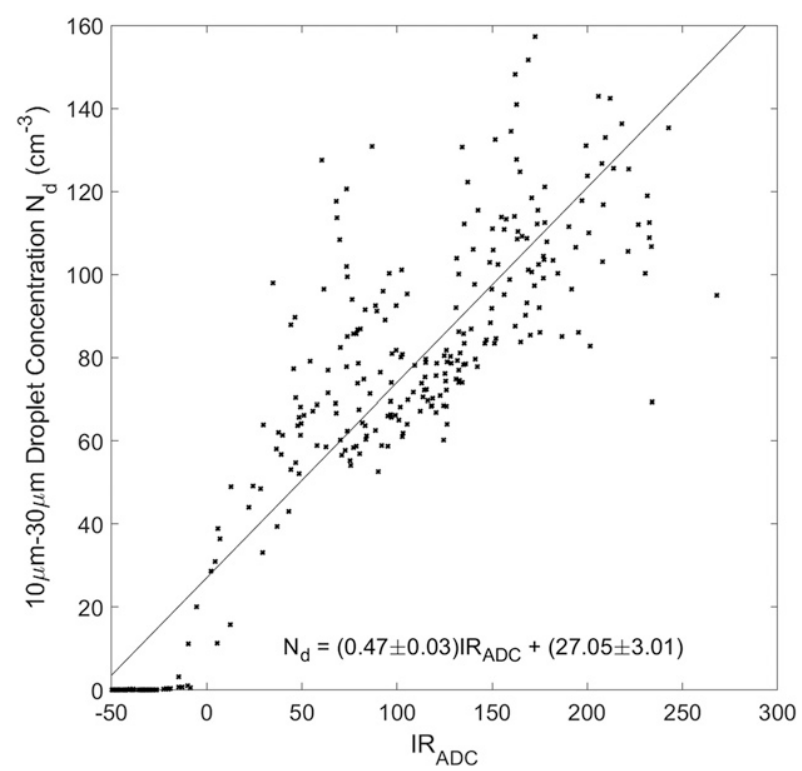

FIG. B2. Comparison of OCS and LOAC devices. Infrared channel ADC counts (IR_ADC) of the OCS plotted against the LOAC integrated droplet count (10-30 $\mu \mathrm{m}$ size range) for all fog events during 14, 15, and 17 Feb 2019.

1200 UTC. Only the infrared channels of the OCS are considered here. The voltage outputs from the OCS's two infrared channels are plotted in red and black, with LOAC droplet count (integrating across the several size bins that span the $10-30 \mu \mathrm{m}$ range) in blue. The time series from the two instruments track well, showing the OCS response to fog droplets.

Figure B2 shows the raw ADC counts $\left(\mathrm{IR}_{\mathrm{ADC}}\right)$, from the infrared channel of one of the cloud sensors plotted against the integrated droplet count $N_{D}$ from the LOAC. A least squares fit to the data allows $N_{D}$ to be calculated from the OCS's $\mathrm{IR}_{\mathrm{ADC}}$, as

$$
N_{D}=(0.47 \pm 0.03) \mathrm{IR}_{\mathrm{ADC}}+(27.05 \pm 3.01) .
$$

Uncertainties in the fit are given by $95 \%$ confidence intervals, implying that the fitted line is robust despite the scatter. Mature fogs often have fairly consistent droplet sizes, hence the scatter evident may indicate changes in the droplet size distribution during the fog evolution.

The derived calibration was applied to both the balloonborne and aircraft OCS, as described in the main text. To reduce the effects of instrumental drift, the drive signal to each LED was made steady (i.e., without square wave modulation) every $4 \mathrm{~min}$ for $10 \mathrm{~s}$, to effectively provide a zero for that channel without changing the balance of currents flowing in the overall device. This reference value was subsequently subtracted from the observed signal. As noise was also present on the OCS channels, the calibration was only applied when the mean backscattered signal from a $10 \mathrm{~s}$ moving window was greater than the mean and one standard deviation of the background noise from the whole flight.

\section{REFERENCES}

Aplin, K. L., K. L. Smith, J. G. Firth, B. J. Kent, M. S. Alexander, and J. P. W. Stark, 2008: Inexpensive optically isolated nanoammeter for use with micro-Newton electric propulsion technology. J. Propul. Power, 24, 891-895, https://doi.org/ 10.2514/1.30994.

Banerjee, S., and M. Levy, 2015: Exact closed-form solution for the electrostatic interaction of two equal-sized charged conducting spheres. J. Phys. Conf., 646, 012016, https://doi.org/ 10.1088/1742-6596/646/1/012016.

Chalmers, J. A., 1967: Atmospheric Electricity. 2nd ed. Pergamon Press, $515 \mathrm{pp}$.

Cheney, M., 2001: Tesla: Man Out of Time. 1st ed. Simon and Schuster, $396 \mathrm{pp}$.

Davis, M. H., 1964: Two charged spherical conductors in a uniform electric field: Forces and field strength. Quart. J. Mech. Appl. Math., 17, 499-511, https://doi.org/10.1093/qjmam/17.4.499.

Duft, D., T. Achtzehn, R. Müller, B. A. Huber, and T. Leisner, 2003: Rayleigh jets from levitated microdroplets. Nature, 421, 128, https://doi.org/10.1038/421128a.

Gaunt, L. F., J. F. Hughes, and N. M. Harrison, 2003: Electrostatic deposition of charged insecticide sprays on electrically isolated insects. J. Electrost., 57, 35-47, https://doi.org/10.1016/ S0304-3886(02)00094-3.

Gunn, R., 1954: Diffusion charging of atmospheric droplets by ions and the resulting combination coefficients. J. Meteor., 11, 339-347, https://doi.org/10.1175/1520-0469(1954)011<0339: DCOADB $>2.0$.CO;2.

Harrison, R. G., 1997: An antenna electrometer system for atmospheric electrical measurements. Rev. Sci. Instrum., 68 , 1599-1603, https://doi.org/10.1063/1.1147932.

_ 2002: A wide-range electrometer voltmeter for atmospheric measurements in thunderstorms and disturbed meteorological conditions. Rev. Sci. Instrum., 73, 482-483, https://doi.org/ 10.1063/1.1435840.

—_, and K. S. Carslaw, 2003: Ion-aerosol-cloud processes in the lower atmosphere. Rev. Geophys., 41, 1012, https://doi.org/ 10.1029/2002RG000114.

— from a balloon platform. Rev. Sci. Instrum., 85, 066104, https:// doi.org/10.1063/1.4882318.

$\longrightarrow,-$, and A. G. Lomas, 2012: Programmable data acquisition system for research measurements from meteorological radiosondes. Rev. Sci. Instrum., 83, 036106, https://doi.org/ 10.1063/1.3697717.

,-- , and M. H. P. Ambaum, 2015: On the microphysical effects of observed cloud edge charging. Quart. J. Roy. Meteor. Soc., 141, 2690-2699, https://doi.org/10.1002/qj.2554.

- G. J. Marlton, K. A. Nicoll, M. W. Airey, and P. D. Williams, 2017: A self-calibrating wide range electrometer for in-cloud measurements. Rev. Sci. Instrum., 88, 126109, https://doi.org/ 10.1063/1.5011177.

— K. A. Nicoll, M. H. P. Ambaum, G. J. Marlton, K. L. Aplin, and M. Lockwood, 2020: Precipitation modification by ionization. Phys. Rev. Lett., 124, 198701, https://doi.org/10.1103/ PhysRevLett.124.198701.

Howard, L., 1843: Lecture fifth. Seven Lectures on Meteorology, 2nd ed, Harvey and Dalton, 100-121.

Ieta, A., and M. Chirita, 2019: Electrohydrodynamic propeller for inatmosphere propulsion; rotational device first flight. J. Electrost., 100, 103352, https://doi.org/10.1016/J.ELSTAT.2019.05.004.

Inculet, I. I., G. S. P. Castle, D. R. Menzies, and R. Frank, 1981: Deposition studies with a novel form of electrostatic crop 
sprayer. J. Electrost., 10, 65-72, https://doi.org/10.1016/ 0304-3886(81)90024-3.

Kent, B. J., K. L. Aplin, L. Wang, S. E. Huq, R. Stevens, A. Malik, and D. Nicolini, 2005: A field effect spacecraft neutralizer for the LISA Pathfinder mission. Classical Quantum Gravity, 22, S483-S486, https://doi.org/10.1088/ 0264-9381/22/10/047.

Lekner, J., 2012: Electrostatics of two charged conducting spheres. Proc. Roy. Soc. London, 468A, 2829-2848, https://doi.org/ 10.1098/RSPA.2012.0133.

Nicoll, K. A., 2013: A self-calibrating electrometer for atmospheric charge measurements from a balloon platform. Rev. Sci. Instrum., 84, 096107, https://doi.org/10.1063/ 1.4821500 .

—_, and R. G. Harrison, 2016: Stratiform cloud electrification: Comparison of theory with multiple in-cloud measurements. Quart. J. Roy. Meteor. Soc., 142, 2679-2691, https://doi.org/ 10.1002/qj.2858.

Phelps, C. T., and B. Vonnegut, 1970: Charging of droplets by impulse corona. J. Geophys. Res., 75, 4483-4490, https:// doi.org/10.1029/JC075i024p04483.

Pruppacher, H. R., and J. D. Klett, 1998: Microphysics of Cloud and Precipitation. 2nd ed. Kluwer Academic Publishers, 954 pp.

Rayleigh, L., 1882: On the equilibrium of liquid conducting masses charged with electricity. London Edinburgh Dublin Philos. Mag. J. Sci., 14, 184-186, https://doi.org/10.1080/14786448208628425.

Renard, J. B., F. Dulac, G. Berthet, T. Lurton, D. Vignelle, F. Jégou, and R. Akiki, 2015: LOAC: A small aerosol optical counter/sizer for ground-based and balloon measurements of the size distribution and nature of atmospheric particles-Part 2: First results from balloon and unmanned aerial vehicle flights.
Atmos. Meas. Tech. Discuss., 8, 1261-1299, https://doi.org/ 10.5194/amtd-8-1261-2015.

Russell, A., 1922: The problem of two electrified spheres. Proc. Phys. Soc. London, 35, 10-29, https://doi.org/10.1088/ 1478-7814/35/1/302.

Strutt, J. W., 1879: The influence of electricity on colliding water drops. Proc. Roy. Soc. London, 28, 406-409, https://doi.org/ 10.1098/RSPL.1878.0146.

Takahashi, T., 1973: Measurement of electric charge of cloud droplets, drizzle, and raindrops. Rev. Geophys. Space Phys., 11, 903-924, https://doi.org/10.1029/RG011i004p00903.

Thomson, W., 1853: On the mutual attraction or repulsion between two electrified spherical conductors. Reprint of Papers on Electrostatics and Magnetism, Macmillan, 86-97.

Tripathi, S. N., and R. G. Harrison, 2001: Scavenging of electrified radioactive aerosol. Atmos. Environ., 35, 5817-5821, https:// doi.org/10.1016/S1352-2310(01)00299-0.

Vaisala, 2018: RS41 datasheet. Vaisala Doc., 2 pp., https://www. vaisala.com/sites/default/files/documents/RS41-SG-DatasheetB211321EN.pdf.

Vonnegut, B., C. B. Moore, G. E. Stout, D. W. Staggs, J. W. Bullock, and W. E. Bradley, 1962a: Artificial modification of atmospheric space charge. J. Geophys. Res., 67, 1073-1083, https://doi.org/10.1029/JZ067i003p01073.

,,,,---- , and,$- 1962 \mathrm{~b}$ : Effect of atmospheric space charge on initial electrification of cumulus clouds. J. Geophys. Res., 67, 3909-3922, https://doi.org/ 10.1029/JZ067i010p03909.

$\mathrm{Xu}, \mathrm{H}$., and Coauthors, 2018: Flight of an aeroplane with solidstate propulsion. Nature, 563, 532-535, https://doi.org/ 10.1038/s41586-018-0707-9. 